\title{
Analgesic antipyretic use among young children in the TEDDY study: no association with islet autoimmunity
}

Markus Lundgren ${ }^{1 *}$ (D) Leigh Johnson Steed ${ }^{2}$, Roy Tamura ${ }^{3}$, Berglind Jonsdottir ${ }^{1}$, Patricia Gesualdo ${ }^{4}$, Claire Crouch $^{5}$, Maija Sjöberg ${ }^{6}$, Gertie Hansson ${ }^{1}$, William A. Hagopian ${ }^{5}$, Anette G. Ziegler ${ }^{7}$, Marian J. Rewers ${ }^{4}$, Åke Lernmark , Jorma Toppari ${ }^{6}$, Jin-Xiong She ${ }^{2}$, Beena Akolkar ${ }^{8}$, Jeffrey P. Krischer ${ }^{3}$, Michael J. Haller ${ }^{9}$, Helena Elding Larsson ${ }^{1}$ and for the TEDDY Study Group

\begin{abstract}
Background: The use of analgesic antipyretics (ANAP) in children have long been a matter of controversy. Data on their practical use on an individual level has, however, been scarce. There are indications of possible effects on glucose homeostasis and immune function related to the use of ANAP. The aim of this study was to analyze patterns of analgesic antipyretic use across the clinical centers of The Environmental Determinants of Diabetes in the Young (TEDDY) prospective cohort study and test if ANAP use was a risk factor for islet autoimmunity.

Methods: Data were collected for 8542 children in the first 2.5 years of life. Incidence was analyzed using logistic regression with country and first child status as independent variables. Holm's procedure was used to adjust for multiplicity of intercountry comparisons. Time to autoantibody seroconversion was analyzed using a Cox proportional hazards model with cumulative analgesic use as primary time dependent covariate of interest. For each categorization, a generalized estimating equation (GEE) approach was used.
\end{abstract}

Results: Higher prevalence of ANAP use was found in the U.S. (95.7\%) and Sweden (94.8\%) compared to Finland (78.1\%) and Germany (80.2\%). First-born children were more commonly given acetaminophen (OR 1.26; $95 \% \mathrm{Cl} 1.07$, $1.49 ; p=0.007$ ) but less commonly Non-Steroidal Anti-inflammatory Drugs (NSAID) (OR 0.86; $95 \% \mathrm{Cl} 0.78,0.95$; $p=0.002$ ). Acetaminophen and NSAID use in the absence of fever and infection was more prevalent in the U.S. (40.4\%; $26.3 \%$ of doses) compared to Sweden, Finland and Germany $(p<0.001)$.

Acetaminophen or NSAID use before age 2.5 years did not predict development of islet autoimmunity by age 6 years (HR 1.02, 95\% Cl 0.99-1.09; $p=0.27$ ). In a sub-analysis, acetaminophen use in children with fever weakly predicted development of islet autoimmunity by age 3 years (HR 1.05; 95\% Cl 1.01-1.09; $p=0.024$ ).

Conclusions: ANAP use in young children is not a risk factor for seroconversion by age 6 years. Use of ANAP is widespread in young children, and significantly higher in the U.S. compared to other study sites, where use is common also in absence of fever and infection.

Keywords: Type 1 diabetes, Analgesics, Islet autoimmunity, Prospective studies

\footnotetext{
* Correspondence: markus.lundgren@med.lu.se

'Department of Clinical Sciences, Diabetes and Celiac disease unit, Lund

University, Clinical Research Centre, Jan Waldenströms gata 35, 20502

Malmö, Sweden

Full list of author information is available at the end of the article
} 


\section{Background}

The administration of analgesic-antipyretic (ANAP) medications to children has been discussed in the literature for decades. Surveys of Canadian and American pediatricians reflect the routine use of acetaminophen and non-steroidal anti-inflammatory drugs (NSAID) for childhood fever and discomfort $[1,2]$. In the 1980s, the term "fever phobia" was used to describe the parental pressure facing pediatric practitioners to manage fever [3]. Parental misconceptions often lead parents to the inappropriate management of fever in their children [4] and parents report the use of antipyretics even when there was minimal or no fever [5] as parents were frequently concerned with the need to maintain a "normal temperature" in their ill child [6]. Nevertheless, additional studies are needed to support this as evidencebased practice [7, 8]. Acetaminophen and NSAID are used widely in children, but limited data exist regarding patterns of use in countries beyond the United States, United Kingdom, France, and Canada [9].

Notably, acetaminophen has been shown to have effects on glucose homeostasis. High doses have been shown to induce hyperglycemia [10], whereas low and chronic doses can lower blood glucose in animal models [11-13]. Possible effects on asthma risk have also been investigated $[14,15]$. NSAIDs have also been shown to lower blood glucose [16, 17], but have additional antiinflammatory properties that could have an impact on the process leading up to T1D [18].

The Environmental Determinants of Diabetes in the Young (TEDDY) Study is an international, multi-center study designed to identify the environmental triggers of T1D in genetically at-risk children [19]. The aim of the current study was to describe the use of ANAP in the TEDDY study, as well as differences in relation to country, birth order (first child versus a child with older siblings) and fever status. Specifically, we sought to examine if the use of ANAP: (1) is associated with risk for islet autoimmunity (IA), (2) differs between countries, (3) is given preferentially to first-born children.

\section{Methods}

The Environmental Determinants of Diabetes in the Young (TEDDY) is a prospective cohort study funded by the National Institutes of Health with the primary goal to identify environmental causes of type 1 diabetes (T1D). It includes six clinical research centers - three in the US: Colorado, Georgia/Florida, Washington and three in Europe: Finland, Germany, and Sweden. Detailed study design and methods have been previously published [19, 20]. Written informed consents were obtained for all study participants from a parent or primary caretaker for genetic screening and participation in prospective follow-up. The study was approved by local
Institutional or Ethics Review Boards (Additional file 1), and is monitored by an External Advisory Board formed by the National Institutes of Health.

\section{Data collection}

The dataset analyzed was the data received by the TEDDY Data Coordinating Center as of December 31, 2014. The total number of subjects enrolled was 8676 . Analysis was restricted to confirmed HLA eligible subjects and subjects with medication information in the first 2 years of age. Out of the enrolled subjects, 134 were missing medication data and were excluded from the analysis. Information regarding first child status was missing for 919 subjects who were also excluded, leaving a total of 7623 subjects (Additional file 2).

Study visits were conducted every 3 months with the first visit occurring between 3 and 4.5 months of age. At each visit, interviewers recorded the name, reason, start date and duration of reported medications for the most recent visit interval. Parents were asked to document fever as either "Yes" or "No" for every illness entry in a "TEDDY Book." The "TEDDY Book" provided written guidance that "Yes" should only be marked for temperature equal to or greater than $38{ }^{\circ} \mathrm{C}$ or $101{ }^{\circ} \mathrm{F}$. Approximately 18 months into the study, these choices were expanded to "Yes - measured," "Yes - not measured," and "No." The rationale for this change was to capture all uses of ANAP, even with low-grade fevers.

Each use of an ANAP was defined as an episode. Recorded medications were categorized based on active ingredient. When analyzing specific substances, all medications containing that particular substance were included. Drugs were also defined and grouped as either analgesic or non-steroidal anti-inflammatory (NSAID) (Additional file 3). Episodes were described as associated with infection and/or fever. Infection was defined as either an ICD-10 code indicating Infection (Additional file 4) or an acute illness designated as infectious within a 15 day time period of the medication date [21]. Fever was defined as either an ICD-10 code of fever associated with the medication or an acute illness associated with fever within a 15-day time period of the medication date.

\section{Islet autoimmunity}

Blood samples were drawn every 3 months between 3 and 48 months of age, and every 6 months thereafter, except for autoantibody positive children, who continued with visits every 3 months. Persistent IA was defined as positive antibodies to insulin (IAA), glutamic acid decarboxylase (GAD65), or insulinoma-associated antigen 2 (IA-2), each analyzed by radiobinding assay [22, 23], on at least 2 consecutive study visits. Two central autoantibody laboratories were used; one in the U.S. (Barbara 
Davis Center for Childhood Diabetes at the University of Colorado) and one in Europe (University of Bristol). All positive islet autoantibodies and 5\% of negative islet autoantibodies were confirmed in both central autoantibody laboratories. Both laboratories have previously demonstrated high sensitivity, specificity [24] and concordance. Positive results in the child that were deemed to be due to maternal IgG transmission were excluded from the IA-positive group.

\section{Statistical methods}

A Cox proportional hazards model was used to assess the impact of ANAP use in the first 90, 180, 365 days of age and 2.5 years of age in the risk of positive autoantibodies through 6 years of age. The number of infections early in life was included as a time dependent covariate [25]. Country was included as a stratification factor in the proportional hazards analyses. Additional covariates included in the model were first-degree relative [26], HLA [27], gender, ever breastfed [28, 29], probiotic use prior to 3 months of age [30], and eight different previously identified single nucleotide polymorphisms [31]. The primary variable of interest was cumulative ANAP use through 2.5 years of life as a time dependent covariate. Included covariates can be seen in Table 1.
The statistical analysis for the number of episodes per year and duration per year excluded subjects for which the first child status was missing. Subjects with a missing duration for a specific analgesic were excluded from the analysis for that analgesic. The statistical analysis of total duration per year was based on log-transformed data to better satisfy the assumptions of the linear models.

Subject incidence was analyzed using logistic regression with country and first child status as independent variables in the model. In both the binary and continuous analyses, pairwise comparisons between countries were conducted using Holm's procedure to adjust for the multiplicity of comparisons. Each specific episode of ANAP usage was classified by concurrent fever (yes/no) or infection (yes/no). Episodes were categorized as associated with Fever, Infection, both Fever and Infection, or neither fever nor infection. For each categorization, a generalized estimating equation (GEE) was used for analysis with country and first child as independent variables in the model. An ignorable working matrix was assumed for the GEE analysis with the empirical sandwich estimate used for the standard errors. Pair-wise comparisons across countries were conducted using Holm's procedure from the GEE analyses. Analyses on the episode level excluded subjects who reported no episodes.

Table 1 Covariates included in the Cox proportionate hazards analysis of time to persistent confirmed autoantibody positivity

\begin{tabular}{|c|c|c|c|}
\hline Fixed Covariates & & Hazard Ratio (95\% Cl) & Wald test $p$-value \\
\hline First-Degree Relative (Ref $=$ No) & & $2.51(2.06,3.30)$ & $<0.001$ \\
\hline \multicolumn{4}{|l|}{ HLA (Ref = DR3/DR4) } \\
\hline & DR4/DR4 & $0.69(0.54,0.88)$ & 0.003 \\
\hline & DR4/DR8 & $0.70(0.54,0.91)$ & 0.008 \\
\hline & DR3/DR3 & $0.46(0.35,0.60)$ & $<0.001$ \\
\hline & All Others & $0.46(0.29,0.72)$ & $<0.001$ \\
\hline Gender (Ref = male) & & $0.77(0.65,0.92)$ & 0.003 \\
\hline \multicolumn{4}{|l|}{ SNP } \\
\hline & RS1004446_a & $0.84(0.74,0.96)$ & 0.010 \\
\hline & RS10517086_a & $1.14(1.00,1.31)$ & 0.050 \\
\hline & RS12708716_g & $0.87(0.76,0.99)$ & 0.034 \\
\hline & RS2292239_a & $1.24(1.09,1.41)$ & $<0.001$ \\
\hline & RS2476601_a & $1.55(1.31,1.83)$ & $<0.001$ \\
\hline & RS2816316_c & $1.07(0.91,1.25)$ & 0.429 \\
\hline & RS3184504_a & $1.33(1.17,1.50)$ & $<0.001$ \\
\hline & RS4948088_a & $0.74(0.53,1.04)$ & 0.086 \\
\hline Ever Breastfed (Ref = No) & & $1.96(1.01,3.81)$ & 0.042 \\
\hline Probiotics <3 Mo Age $(\operatorname{Ref}=$ No) & & $0.72(0.55,0.94)$ & 0.015 \\
\hline \multicolumn{4}{|l|}{ Time Dependent Covariates } \\
\hline Cumulative Number of Infections & & $1.02(0.99,1.03)$ & 0.407 \\
\hline Cumulative Weeks Analgesic Use & & $1.02(0.99,1.04)$ & 0.269 \\
\hline
\end{tabular}

Number of persistent confirmed cases $=511$

${ }^{\mathrm{a}} \mathrm{Ho:} \mathrm{Hazard} \mathrm{Ratio}=1$ 
Statistical analysis was performed using SAS version 9.3 (SAS Institute Inc., Cary, NC, U.S.A).

\section{Results}

\section{Use of ANAP below the age of 2.5 years}

The use of both acetaminophen and NSAIDs were very common in the study population. In the total cohort, $87.8 \%$ of children reported the use of acetaminophen and $45.4 \%$ of NSAIDs before the age of 2.5 years. The mean number of treatment episodes per year was $3.6 \pm 2.1$ and mean duration of treatment $8.5 \pm 10.8$ days per year in the total cohort (Fig. 1a-c).

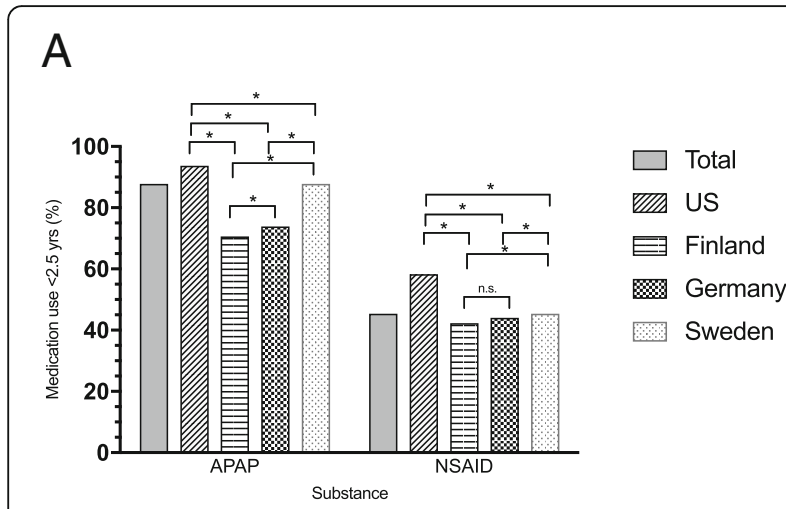

B
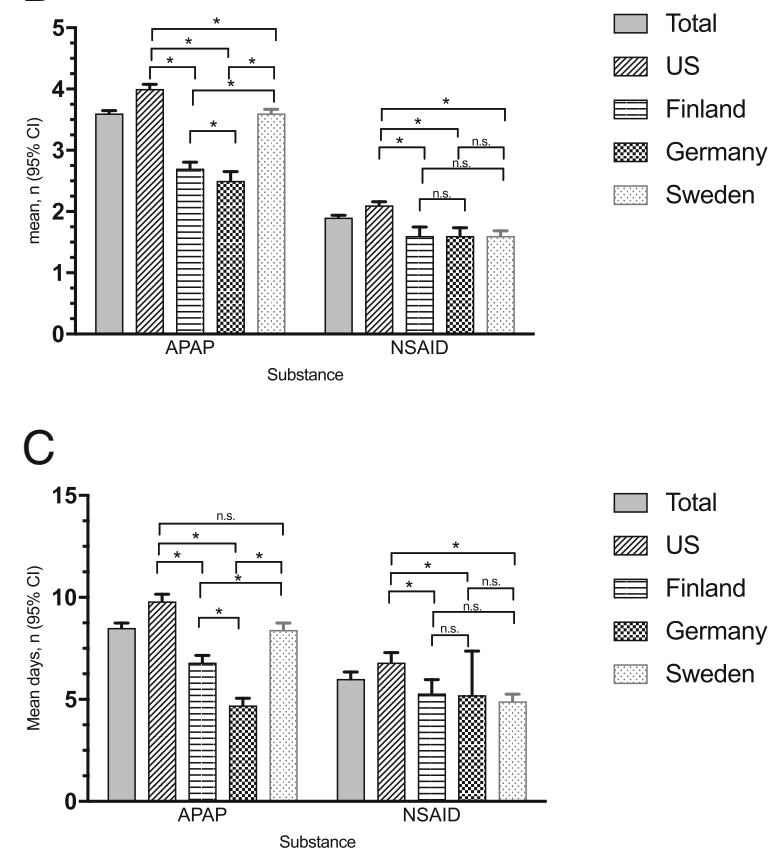

Fig. 1 Use of ANAP below 2,5 years of age. *:p < 0.05, n.s.: non significant. All significances corrected for multiple comparisons using Holm procedure. a Prevalence of analgesic/antipyretic use. $\mathbf{b}$ Treatment episodes per year. c Duration of medication use per year

\section{Acetaminophen use}

Swedish parents reported a significantly higher prevalence of acetaminophen use (94.5\%), followed by U.S. (93.7\%), Finnish (73.9\%), and German parents (70.1\%). Prevalence differed between all countries (Finland vs. Germany: $p=0.035$, all other $p<0.001)$. U.S. parents reported the highest number of treatment episodes per year and highest total duration of treatment per year (mean $4.0 \pm 2.3$ episodes; mean $9.8 \pm 13.5$ days), followed by Swedish (mean $3.6 \pm 2.1$ episodes; mean $8.4 \pm 8.6$ days), Finnish (mean $2.7 \pm 1.9$ episodes; mean $6.8 \pm 6.4$ days), and German parents (mean $2.5 \pm 1.6$ episodes; mean $4.7 \pm 3.7$ days). All country differences, according to number of treatment episodes, were statistically significant (Finland vs. Germany: $p=0.014$, all others $p<0.001$ ) (Fig. 1). Children born as the first child in the family had more often been given acetaminophen during their first 2.5 years of life compared to children with older siblings (OR 1.26; 95\% CI 1.07, $1.49 ; p=0.007)$. The number of episodes of treatment with acetaminophen was also higher (difference in least square means $0.15 ; 95 \%$ CI 0.05 , 9.24; $p=0.003$ ). No difference could be seen regarding the number of days treated (difference in least square means $0.11 ; 95 \%$ CI $-0.38,0.60 ; p=0.111$ ).

\section{NSAID use}

The highest prevalence of NSAID use was reported by U.S. parents (58.3\%), followed by German (44.1\%), Finnish (42.3\%), and Swedish parents (29.0\%). All country differences, except between Finland and Germany, were statistically significant (Finland vs. Germany: $p=0.177$, all others $p<0.001)$. U.S. parents reported the highest number of treatment episodes with NSAID per year (mean $2.1 \pm 1.4$ episodes; mean $6.8 \pm 11.2$ days), followed by Swedish, Finnish, and German parents (mean $1.6 \pm 1.2$; mean $1.6 \pm 1.2$; mean $1.6 \pm 1.1$ ) Total duration of treatment was highest in the U.S. (mean $6.8 \pm 11.2$ days), followed by Finland (mean $5.3 \pm 9.3$ days), Germany (mean $5.2 \pm 17.2$ days), and Sweden (mean $4.9 \pm 4.8$ days). Both the mean number of treatment episodes and mean total duration of treatment were significantly higher in the U.S. compared to the other countries $(p<0.001)$. No other significant country differences could be seen (Fig. 1). The prevalence of NSAID use during the first 2.5 years of life were lower in firstborn children (OR 0.86; 95\% CI 0.78, 0.95; $p=0.002$ ) and they were also treated fewer times (difference in least square means -0.14; $95 \%$ CI $-0.22,-0.05$; $p=0.001)$. No differences could be seen regarding the number of days treated (difference in least square means -0.22 ; $95 \%$ CI $-0.92,0.48 ; p=0.143$ ). 


\section{Differences in use for febrile/infectious episodes and noninfectious use}

In the total cohort, $74.1 \%$ of acetaminophen use and $82.0 \%$ of NSAID use was given in conjunction with either fever, infection or both, with $43.8 \%$ acetaminophen use and 51.0\% NSAID episodes being combined fever and infection. U.S. parents reported a significantly higher proportion of doses given without fever or infection for both acetaminophen (40.4\%) and NSAID (26.3\%) compared to the other three countries $(p<0.001)$. Acetaminophen use in feverish infectious episodes had the highest proportion among German and Swedish children (68.5\% and $63.2 \%$;), followed by Finland with $57.9 \%$ and the U.S. with $23.5 \%$ (all $p$-values for differences between countries were $p<0.001$, except between Germany and Swedenwas $p=0.003$ ).

For NSAID use without fever or infection, the U.S. parents reported the highest proportion (26.3\%), followed by Finland (7.7\%), Germany (5.9\%), and Sweden (3.7\%) (difference between Finland and Sweden $p=0.006$; between Germany and Sweden $p=0.01$; all others $p<0.001$ ) (Fig. 2, Table 2).

\section{Islet autoimmunity}

Hazard ratios for islet autoimmunity were estimated for cumulative use of acetaminophen and NSAID with or without concomitant fever and for a joint variable of cumulative total ANAP use with or without fever. A significant hazard was only found for use of acetaminophen in the presence of fever for islet autoimmunity at age 3 years (HR 1.05; 95\% CI 1.01-1.09; $p=0.024$ ). The hazard was not significant for islet autoimmunity at 6 years of age $(p=0.193)$.

Separate analysis of exposure before 90, 180 and 365 days of life found a significant hazard for seroconversion at age 3 years (HR 1.06; 95\% CI 1.00-1.12; $p=0.011)$ for use of acetaminophen with concurrent fever before 1 year of age, but not before 90 or 180 days

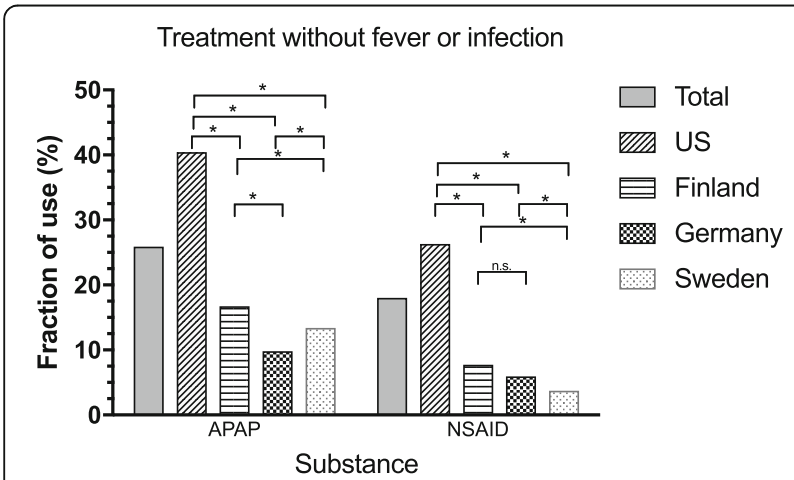

Fig. 2 Fraction of treatment without fever and infection. * $p<0.05$, n.s.: non-significant. All significances corrected for multiple comparisons using Holm procedure of life ( $p=0.91$ and $p=0.54$, respectively). No other significant hazards could be seen for treatment with acetaminophen or NSAID in the presence or absence of fever (Table 3).

\section{Discussion}

In this study, we investigated the use of ANAP in children below the age of 2.5 years, and the impact of such use on the development of islet autoimmunity before 6 years of age in the large, longitudinal, international TEDDY cohort.

The widespread use of acetaminophen among young children has been of interest due not only to possible side effects, but also possible immunological effects. Several papers have investigated the impact on immune response and the development of autoimmunity $[11,12,32,33]$. The data on childhood asthma is conflicting, with some studies showing an increased risk and others showing none $[14,15,34]$. The use of prophylactic acetaminophen in conjunction with childhood vaccinations has also shown possible effects on antibody responses [1, 7, 35]. In this study, we found a significant but weak increased hazard ratio associated with the use of acetaminophen and concomitant fever before the age of 2.5 years and persistent confirmed islet autoimmunity at age 3 years. However, this effect was not seen with islet autoimmunity at age 6 years or if acetaminophen was used for other reasons. It is therefore unlikely, although possible, that this is a true effect. The type of infection causing the fever may be a confounding factor. No such effect was seen with the use of NSAIDs or the combination of acetaminophen and NSAIDs, either when given with or without fever.

The use of acetaminophen and NSAIDs for the treatment of children has been previously described from a medical standpoint $[36,37]$. On the other hand, very little has been described regarding practical use in the pediatric population. This analysis within a large international cohort provides some of the first data regarding pediatric use of ANAP. As expected,the majority of treatment episodes for this young cohort were in conjunction with fever and/or infection. It is worth mentioning that there are significant differences between the TEDDY countries regarding the use of both acetaminophen and NSAIDs. The U.S. stands out for both greater prevalence of use and greater number of episodes of treatment per year, followed closely by Sweden in regards to acetaminophen use. U.S. parents were also just as likely to report using these medications during episodes associated with infection than non-infectious episodes. Additionally, they were more likely to use ANAP when there was no associated fever. It may be a common practice of American physicians to prescribe a 
Table 2 Summary of treatment episodes associated with fever and/or infection

\begin{tabular}{|c|c|c|c|c|c|c|c|c|c|c|c|c|c|}
\hline & & & \multirow[t]{2}{*}{ US } & \multirow[t]{2}{*}{ Finland } & \multirow[t]{2}{*}{ Germany } & \multirow[t]{2}{*}{ Sweden } & \multirow[t]{2}{*}{ Total Cohort } & \multicolumn{6}{|c|}{ Country differences } \\
\hline & & & & & & & & $\overline{U-F}$ & U-G & U-S & $\mathrm{F}-\mathrm{G}$ & $\mathrm{F}-\mathrm{S}$ & G-S \\
\hline \multicolumn{2}{|l|}{ Total episodes } & $\mathrm{n}$ & 25,340 & 7427 & 2091 & 17,285 & 52,643 & & & & & & \\
\hline \multirow[t]{3}{*}{ Acetaminophen } & Fever and infection & $\mathrm{n}$ & 4272 & 2907 & 983 & 9224 & 17,386 & $<0.001$ & $<0.001$ & $<0.001$ & $<0.001$ & $<0.001$ & 0.003 \\
\hline & Fever or infection & & 6557 & 1277 & 311 & 3421 & 12,066 & & & & & & \\
\hline & No fever and no infection & $n$ & 7348 & 841 & 141 & 1953 & 10,283 & $<0.001$ & $<0.001$ & $<0.001$ & $<0.001$ & 0.006 & 0.01 \\
\hline \multirow[t]{3}{*}{ NSAID } & Fever and infection & $n$ & 2680 & 1273 & 477 & 1572 & 6002 & $<0.001$ & $<0.001$ & $<0.001$ & $<0.001$ & $<0.001$ & 0.024 \\
\hline & Fever or infection & $\mathrm{n}$ & 2472 & 717 & 125 & 330 & 3644 & & & & & & \\
\hline & No fever and no infection & $\mathrm{n}$ & 1841 & 167 & 38 & 74 & 2120 & $<0.001$ & $<0.001$ & $<0.001$ & 0.174 & $<0.001$ & 0.041 \\
\hline
\end{tabular}

Country differences: $\mathrm{U}=\mathrm{US}, \mathrm{G}=$ Germany, $\mathrm{F}=$ Finland, $\mathrm{S}=$ Sweden, Country differences described as $p$-value for difference between the respective countries

combination therapy approach to the use of analgesics and antipyretics forthe sustained management of fever. However, parents may then assume that even prophylactic use should be a combination therapy.

We also found that first-born children were preferentially given acetaminophen, both in prevalence of use and in the higher number of treatment episodes than for their younger siblings. The inverse relationship was observed for NSAID use, in which both the prevalence and number of treatment episodes were lower for first-born children. We can only speculate on the possible rationale behind this finding since, to our knowledge, no earlier study has presented similar data. It is possible that acetaminophen is perceived by first-time parents as a better tolerated treatmentthan NSAIDS, a perception that fades by the time younger siblings require treatment.

Country-specific differences in the use of analgesics may be culturally influenced. The lower incidence of use of all standard analgesics in Germany could reflect the prevalence of Complimentary Alternative Medicine (CAM) in this country. According

Table 3 Hazard ratios for seroconversion to persistent islet autoimmunity at 3 and 6 years of age for analgesic variables of interest

\begin{tabular}{|c|c|c|c|}
\hline \multirow[t]{3}{*}{ Analgesic Variable } & \multirow{3}{*}{$\begin{array}{l}\text { Exposed } \\
\text { subjects n } \\
(\%)\end{array}$} & 3 Year Analysis & 6 Year Analysis \\
\hline & & 398 antibody + subjects & 511 antibody + subjects \\
\hline & & HR $(95 \% \mathrm{Cl}) p$-value & HR (95\% Cl) p-value \\
\hline Acetaminophen, any exposure & $7496(87.8 \%)$ & $1.01(0.97,1.05) 0.603$ & $1.01(0.98,1.05) 0.576$ \\
\hline Acetaminophen with fever + infection & $5179(60.6 \%)$ & $1.05(1.01,1.09) 0.022$ & $1.03(0.99,1.08) 0.189$ \\
\hline Exposed $<90$ days of life & $220(2.6 \%)$ & $0.97(0.59,1.61) 0.914$ & $1.00(0.68,1.46) 0.986$ \\
\hline Exposed $<180$ days of life & $1519(17.8 \%)$ & $1.07(0.87,1.32) 0.542$ & $1.06(0.88,1.27) 0.527$ \\
\hline Exposed $<365$ days of life & 3795 (44.4\%) & $1.06(1.00,1.12) 0.011$ & $1.05(0.99,1.11) 0.101$ \\
\hline Acetaminophen without fever or infection & $5941(69.6 \%)$ & $1.02(0.98,1.06) 0.346$ & $1.01(0.96,1.05) 0.769$ \\
\hline Exposed $<90$ days of life & $4016(47.0 \%)$ & $1.00(0.90,1.11) 0.994$ & $0.99(0.85,1.14) 0.837$ \\
\hline Exposed $<180$ days of life & $4597(53.8 \%)$ & $0.98(0.84,1.14) 0.814$ & $0.97(0.84,1.13) 0.729$ \\
\hline Exposed $<365$ days of life & $5310(62.2 \%)$ & $1.03(0.99,1.06) 0.114$ & $1.02(0.99,1.06) 0.228$ \\
\hline NSAID, any exposure & $3874(45.4 \%)$ & $1.01(0.97,1.05) 0.753$ & $1.01(0.97,1.04) 0.763$ \\
\hline NSAID with fever + infection & $2652(31.0 \%)$ & $1.01(0.97,1.05) 0.673$ & $1.01(0.98,1.05) 0.459$ \\
\hline Exposed $<90$ days of life & $22(0.3 \%)$ & $1.01(0.92,1.10) 0.897$ & $1.00(0.92,1.09) 0.960$ \\
\hline Exposed $<180$ days of life & $223(2.6 \%)$ & $0.99(0.88,1.11) 0.822$ & $1.00(0.94,1.07) 0.927$ \\
\hline Exposed $<365$ days of life & $1318(15.4 \%)$ & $1.01(0.97,1.06) 0.530$ & $1.02(0.98,1.05) 0.378$ \\
\hline NSAID without fever or infection & $1955(22.9 \%)$ & $1.00(0.96,1.05) 0.856$ & $1.01(0.97,1.05) 0.623$ \\
\hline Exposed $<90$ days of life & $222(2.6 \%)$ & $1.00(0.88,1.12) 0.943$ & $0.99(0.88,1.12) 0.874$ \\
\hline Exposed $<180$ days of life & $458(5.4 \%)$ & $0.99(0.88,1.11) 0.815$ & $1.00(0.94,1.07) 0.956$ \\
\hline Exposed $<365$ days of life & $1120(13.1 \%)$ & $1.01(0.96,1.06) 0.824$ & $1.01(0.97,1.05) 0.638$ \\
\hline Any analgesic, any exposure & $7744(91 \%)$ & $1.02(0.99,1.05) 0.130$ & $1.02(0.99,1.04) 0.267$ \\
\hline Any analgesic with fever + infection & 5699 (67\%) & $1.06(0.97,1.15) 0.219$ & $1.02(0.94,1.10) 0.667$ \\
\hline
\end{tabular}


to a cross-sectional survey of German physicians in 2007, more than two-thirds of patients in Germany use CAM provided either by physicians or non-medical practitioners ("Heilpraktiker") [38]. In 2007, only $40 \%$ of adults in the U.S. had used CAM therapy in the past 12 months. Children in the U.S. whose parents used CAM were almost five times as likely (23.9\%) to use CAM than children whose parent did not use CAM (5.1\%) [39]. The reasons underlying greater use of acetaminophen among Swedish parents is more unclear but may be the result of acetaminophen being widely available and perceived as safe and effective.

The TEDDY study is one of the largest longitudinal pediatric cohorts studied. The data analyzed herein has been collected from parent reports given in writing and after discussion with a TEDDY nurse. For participating children, missing data is uncommon. Follow-up is continuous from age 3 months which minimizes recall bias. The possibility to adjust for confounding factors in the statistical analysis is great due to the availability of comprehensive data on the child's living conditions. All previously described risk factors for T1D and islet autoimmunity are also entered into the statistical analysis of the effect of analgesics on islet autoimmunity.

The limitations of this study include our reliance on parent-reported symptoms and dosages of ANAP. The size of the cohort also makes it challenging to confirm diagnoses and treatment plans via patient records. Notably, most of the reported infections were presumed to be viral infections for which no medical advice had been sought. In addition, the widespread use of ANAP in this age group poses a significant statistical problem since the exposed group widely surpasses the non-exposed group. Even with the large sample size, the resulting correlation between IA and acetaminophen in combination with fever must therefore be interpreted with caution.

\section{Conclusions}

In conclusion, the use of ANAP to treat fever and infection is widespread in the TEDDY cohort but shows significant differences depending on study site. The prevalence of use of both acetaminophen and NSAIDs are highest in the U.S. and lowest in Finland and Germany. Use of both NSAIDs and acetaminophen for non-infectious purposes are significantly more common among children in the U.S. compared to those in Europe. No convincing effect on risk for autoimmunity can be seen in the analysis except for a small effect by acetaminophen in combination with fever, and then only for autoimmunity at 3 years of age.

\section{Additional files}

Additional file 1: Ethical review boards and Committees granting ethical approval to the TEDDY study. Listing of all ethical review boards and committes that has granted approval to the TEDDY study for the respective sites. (DOCX $59 \mathrm{~kb}$ )

Additional file 2: Characteristics of the subjects used in analysis for analgesic use and islet cell autoimmunity. A table the prevalence of covariates in the present analysis including HLA-DQ genotype, Gender, first degree relative, breastfeeding, probiotic use and presence of included single nucleotide polymorphisms. (DOCX $106 \mathrm{~kb}$ )

Additional file 3: List of Drugs defined as analgesics used in first 2.5 years in the TEDDY study. List of all included drugs, recorded to having been given to TEDDY children before age 2.5 years and classified as analgesics. Drugs classified as NSAID's are marked with a star $\left(^{*}\right)$. (DOCX $30 \mathrm{~kb}$ )

Additional file 4: List of all ICD-10 codes, recorded among TEDDY children before age 2.5 years, and classified as an infection. (DOCX $72 \mathrm{~kb}$ )

\section{Abbreviations}

ANAP: Analgesic-Antipyretic; CAM: Complimentary alternative medicine; GEE: Generalized estimating eq.i IA: Islet Autoimmunity; NSAID: Non-steroidal anti-inflammatory drugs; T1D: Type 1 Diabetes; TEDDY: The environmental determinants of diabetes in the young study

\section{Acknowledgements}

The Teddy study group.

Funded by U01 DK63829, U01 DK63861, U01 DK63821, U01 DK63865, U01 DK63863, U01 DK63836, U01 DK63790, UC4 DK63829, UC4 DK63861, UC4 DK63821, UC4 DK63865, UC4 DK63863, UC4 DK63836, UC4 DK95300, UC4 DK100238, UC4 DK106955, and Contract No. HHSN267200700014C from the National Institute of Diabetes and Digestive and Kidney Diseases (NIDDK), National Institute of Allergy and Infectious Diseases (NIAID), National Institute of Child Health and Human Development (NICHD), National Institute of Environmental Health Sciences (NIEHS), Juvenile Diabetes Research

Foundation (JDRF), and Centers for Disease Control and Prevention (CDC). This work supported in part by the NIH/NCATS Clinical and Translational Science Awards to the University of Florida (UL1 TR000064) and the University of Colorado (UL1 TR001082).

Colorado Clinical Center: Marian Rewers, M.D., Ph.D., PI 1, 4-6, 10, 11 , Kimberly ${\text { Bautista }{ }^{12} \text {, Judith Baxter }{ }^{9}}_{10}, 12,15$, Ruth Bedoy ${ }^{2}$, Daniel Felipe-Morales, Kimberly Driscoll, Ph.D. ${ }^{9}$, Brigitte I. Frohnert, M.D. ${ }^{2,}{ }^{14}$, Patricia Gesualdo ${ }^{2,}$ 6, 12 ,

14, 15 , Michelle Hoffman ${ }^{12-14}$, Rachel Karban ${ }^{12}$, Edwin Liu, M.D. ${ }^{13}$, Jill Norris, Ph.D.' 2, 32, Adela Samper-Imaz, Andrea Steck, M.D. 3, 14, Kathleen Waugh 6, 7. 12, 15 , Hali Wright ${ }^{12}$. University of Colorado, Anschutz Medical Campus, Barbara Davis Center for Childhood Diabetes.

Finland Clinical Center: Jorma Toppari, M.D., Ph.D., Pl ${ }^{¥ \wedge 1,4,11,14}$, Olli G. Simell,

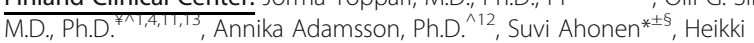
Hyöty, M.D., Ph.D.* ${ }^{* 6}$, Jorma Ilonen, M.D., Ph.D. ${ }^{¥ 3}$, Sanna Jokipuu^, Tiina Kallio^, Leena Karlsson^, Miia Kähönen ${ }^{\mu x}$, Mikael Knip, M.D., Ph.D. ${ }^{* \pm 5}$, Lea Kovanen $^{* \pm \S}$, Mirva Koreasalo* ${ }^{* \pm 2}$, Kalle Kurppa, M.D., Ph.D.* ${ }^{* 13}$, Tiina Latva$a_{h}{ }^{\mu \alpha}$, Maria Lönnrot, M.D., Ph.D. ${ }^{* \pm 6}$, Elina Mäntymäki ${ }^{\wedge}$, Katja Multasuo ${ }^{\mu \alpha}$, Juha Mykkänen, Ph.D. ${ }^{* 3}$, Tiina Niininen ${ }^{ \pm * 12}$, Sari Niinistö ${ }^{ \pm \S}$, Mia Nyblom ${ }^{* \pm}$, Petra Rajala^, Jenna Rautanen ${ }^{ \pm \S}$, Anne Riikonen*£, Mika Riikonen^, Jenni Rouhiainen^, Minna Romo^, Tuula Simell, Ph.D., Ville Simell^¥13, Maija Sjöberg $^{¥ \wedge 12,14}$, Aino Stenius ${ }^{\mu \ltimes 12}$, Maria Leppänen`, Sini Vainionpää^, Eeva $\operatorname{Varjonen}^{¥ \wedge 12}$, Riitta Veijola, M.D., Ph.D. ${ }^{\mu x 14}$, Suvi M. Virtanen, M.D., Ph.D. ${ }^{* £ 2}$, Mari Vähä-Mäkilä^, Mari Åkerlund ${ }^{* \pm \S}$, Katri Lindfors, Ph.D.*13 ${ }^{*}$ University of Turku, *University of Tampere, "MUniversity of Oulu, ^Turku University Hospital, Hospital District of Southwest Finland, ${ }^{ \pm}$Tampere University Hospital, "Oulu University Hospital, §National Institute for Health and Welfare, Finland, "University of Kuopio.

Georgia/Florida Clinical Center: Jin-Xiong She, Ph.D., PI 1, 3, 4, 11, Desmond Schatz, M.D.* ${ }^{* 4,5,1,8}$, Diane Hopkins ${ }^{12}$, Leigh Steed ${ }^{12-15}$, Jamie Thomas ${ }^{* 6,} 12$ Janey Adams*12, Katherine Silvis ${ }^{2}$, Michael Haller, M.D.*14, Melissa Gardiner, Richard Mclndoe, Ph.D., Ashok Sharma, Joshua Williams, Gabriela Young, Stephen W. Anderson, M.D. , Laura Jacobsen, M.D. ${ }^{* 14}$ Center for Biotechnology and Genomic Medicine, Augusta University. *University of Florida, ^Pediatric Endocrine Associates, Atlanta. 
Germany Clinical Center: Anette G. Ziegler, M.D., PI 1, 3, 4, 11 , Andreas Beyerlein, Ph.D. ${ }^{2}$, Ezio Bonifacio Ph.D.*5, Michael Hummel, M.D. ${ }^{13}$, Sandra Hummel, Ph.D. ${ }^{2}$, Kristina Foterek ${ }^{* 2}$, Nicole Janz, Mathilde Kersting, Ph.D.², Annette Knopff', Sibylle Koletzko, M.D. ${ }^{113}$, Claudia Peplow ${ }^{12}$, Roswith Roth, Ph.D. ${ }^{9}$, Marlon Scholz, Joanna Stock ${ }^{9}, 12,14$, Katharina Warncke, M.D. ${ }^{14}$, Lorena Wendel, Christiane Winkler, Ph.D. ${ }^{2}$ 12, 15 . Forschergruppe Diabetes e.V. and Institute of Diabetes Research, Helmholtz Zentrum München, and Klinikum rechts der Isar, Technische Universität München. ${ }^{*}$ Center for Regenerative Therapies, TU Dresden, "Dr. von Hauner Children's Hospital, Department of Gastroenterology, Ludwig Maximillians University Munich, ${ }^{*}$ Research Institute for Child Nutrition, Dortmund.

Sweden Clinical Center: Åke Lernmark, Ph.D., PI 1, 3-6, 8, 10, 11, 15, Daniel Agardh, M.D., Ph.D. ${ }^{13}$, Carin Andrén Aronsson", 12,13, Maria Ask, Jenny Bremer, Ulla-Marie Carlsson, Corrado Cilio, Ph.D., M.D. ${ }^{5}$, Emelie Ericson-Hallström, Lina Fransson, Thomas Gard, Joanna Gerardsson, Rasmus Bennet, Monica Hansen, Gertie Hansson, Susanne Hyberg, Fredrik Johansen, Berglind Jonsdottir, M.D., Helena Elding Larsson, M.D., Ph.D. 6,14, Marielle Lindström, Markus Lundgren, M.D. ${ }^{14}$, Maria Månsson-Martinez, Maria Markan, Jessica Melin ${ }^{12}$, Zeliha Mestan, Karin Ottosson, Kobra Rahmati, Anita Ramelius, Falastin Salami, Sara Sibthorpe, Birgitta Sjöberg, Ulrica Swartling, Ph.D.,12, Evelyn Tekum Amboh, Carina Törn, Ph.D. ${ }^{3,15}$, Anne Wallin, Åsa Wimar ${ }^{12,14}$, Sofie Åberg. Lund University.

Washington Clinical Center: William A. Hagopian, M.D., Ph.D., PI 1,3,4, 5, 6,7,11,13, ${ }^{14}$, Michael Killiann ${ }^{6,1,12,13}$, Claire Cowen Crouch ${ }^{12,14,15}$, Jennifer Skidmore ${ }^{2}$, Josephine Carson, Maria Dalzell, Kayleen Dunson, Rachel Hervey, Corbin Johnson, Rachel Lyons, Arlene Meyer, Denise Mulenga, Alexander Tarr, Morgan Uland, John Willis. Pacific Northwest Diabetes Research Institute. Pennsylvania Satellite Center: Dorothy Becker, M.D., Margaret Franciscus, MaryEllen Dalmagro-Elias Smith ${ }^{2}$, Ashi Daftary, M.D., Mary Beth Klein, Chrystal Yates. Children's Hospital of Pittsburgh of UPMC.

Data Coordinating Center: Jeffrey P. Krischer, Ph.D.,PI ${ }^{1,4,5,10,11}$, Michael Abbondondolo, Sarah Austin-Gonzalez, Maryouri Avendano, Sandra Baethke, Rasheedah Brown ${ }^{12,15}$, Brant Burkhardt, Ph.D. ${ }^{5,6}$, Martha Butterworth'2, Joanna Clasen, David Cuthbertson, Christopher Eberhard, Steven Fiske', Dena Garcia, Jennifer Garmeson, Veena Gowda, Kathleen Heyman, Francisco Perez Laras, Hye-Seung Lee, Ph.D. 1,2,13,15, Shu Liu, Xiang Liu, Ph.D. 2,3,9,14, Kristian Lynch, Ph.D. 5,6,9,15, Jamie Malloy, Cristina McCarthy ${ }^{12,15}$, Steven Meulemans, Hemang Parikh, Ph.D. ${ }^{3}$, Chris Shaffer, Laura Smith, Ph.D., ${ }^{92}$, Susan Smith ${ }^{12,15}$, Noah Sulman, Ph.D., Roy Tamura, Ph.D. ${ }^{1,2,13}$, Ulla Uusitalo, Ph.D. ${ }^{2,15}$, Kendra Vehik, Ph.D. 4,5,6,14,15, Ponni Vijayakandipan, Keith Wood, Jimin Yang, Ph.D., R.D., 15 . Past staff: Lori Ballard, David Hadley, Ph.D., Wendy McLeod. University of South Florida.

Project scientist: Beena Akolkar, Ph.D. 1,3,4,6,7,10,11. National Institutes of Diabetes and Digestive and Kidney Diseases.

Autoantibody Reference Laboratories: Liping Yu, M.D. ${ }^{\wedge 5}$, Dongmei Miao, M.D.`, Polly Bingley, M.D., FRCP*5, Alistair Williams*, Kyla Chandler*, Saba Rokni*, Claire Williams*, Rebecca Wyatt*, Gifty George*, Sian Grace*. ^Barbara Davis Center for Childhood Diabetes, University of Colorado Denver, *School of Clinical Sciences, University of Bristol UK.

HLA Reference Laboratory: Henry Erlich, Ph.D. ${ }^{3}$, Steven J. Mack, Ph.D., Anna Lisa Fear. Center for Genetics, Children's Hospital Oakland Research Institute. Repository: Sandra Ke, Niveen Mulholland, Ph.D. NIDDK Biosample Repository at Fisher BioServices.

SNP Laboratory: Stephen S. Rich, Ph.D. ${ }^{3}$, Wei-Min Chen, Ph.D. ${ }^{3}$, Suna Onengut-Gumuscu, Ph.D. ${ }^{3}$, Emily Farber, Rebecca Roche Pickin, Ph.D., Jordan Davis, Dan Gallo, Jessica Bonnie, Paul Campolieto. Center for Public Health Genomics, University of Virginia.

Other contributors: Kasia Bourcier, Ph.D. ${ }^{5}$, National Institutes of Allergy and Infectious Diseases. Thomas Briese, Ph.D., ${ }^{6,15}$, Columbia University. Suzanne Bennett Johnson, Ph.D., ${ }^{92}$, Florida State University. Eric Triplett, Ph.D. ${ }^{6}$, University of Florida.

Committees:

${ }^{1}$ Ancillary Studies, ${ }^{2}$ Diet, ${ }^{3}$ Genetics, ${ }^{4}$ Human Subjects/Publicity/Publications, ${ }^{5}$ Immune Markers, ${ }^{6}$ Infectious Agents, ${ }^{7}$ Laboratory Implementation, ${ }^{8}$ Maternal Studies, ${ }^{9}$ Psychosocial, ${ }^{10}$ Quality Assurance, ${ }^{11}$ Steering, ${ }^{12}$ Study Coordinators,

${ }^{13}$ Celiac Disease, ${ }^{14}$ Clinical Implementation, ${ }^{15}$ Quality Assurance

Subcommittee on Data Quality.

\section{Funding}

Funded by U01 DK63829, U01 DK63861, U01 DK63821, U01 DK63865, U0 DK63863, U01 DK63836, U01 DK63790, UC4 DK63829, UC4 DK63861, UC4
DK63821, UC4 DK63865, UC4 DK63863, UC4 DK63836, UC4 DK95300, UC4 DK100238, UC4 DK106955, and Contract No. HHSN267200700014C from the National Institute of Diabetes and Digestive and Kidney Diseases (NIDDK), National Institute of Allergy and Infectious Diseases (NIAID), National Institute of Child Health and Human Development (NICHD), National Institute of Environmental Health Sciences (NIEHS), Juvenile Diabetes Research Foundation (JDRF), and Centers for Disease Control and Prevention (CDC). This work supported in part by the NIH/NCATS Clinical and Translational Science Awards to the University of Florida (UL1 TR000064) and the University of Colorado (UL1 TR001082)

\section{Availability of data and materials}

The data that support the findings of this study are available from the NIDDK repository (http://niddkrepository.org) approximately 6 months after the manuscript has appeared in print. Access for the data submitted to the NIDDK Data Repository will be determined by the NIDDK. All investigators who receive TEDDY resources must agree to acknowledge the TEDDY Study and the NIDDK central repository. This approach is fully compliant with the $\mathrm{NIH}$ public data sharing policy (http://grants.nih.gov/grants/policy/data_sharing).

\section{Authors' contributions}

$M L$ researched the data and wrote the manuscript. LJS was involved in the drafting of the manuscript and reviewed/edited the manuscript. RT made the statistical analyses, researched data and reviewed/edited the manuscript. $M H, H E L, B J, P G, C C, M S, G H$ researched data and reviewed/edited the manuscript. WH, AGZ, MR, $\AA \mathrm{L}, \mathrm{JT}, \mathrm{JS}, \mathrm{BA}$ and JK designed the study, researched data, and reviewed/edited the manuscript. All authors approved the final manuscript as submitted and agree to be accountable for all aspects of the work.

\section{Competing interests}

The authors have no conflicts of interest relevant to this article to disclose. The funding agencies did not include any input into the design and conduct of the study; collection, management, analysis, or interpretation of data; or preparation, review, or approval of manuscript.

\section{Consent for publication}

Not applicable.

Ethics approval and consent to participate

The study was approved by the local Institutional or Ethics Review Boards and is monitored by an External Advisory Board formed by the National Institutes of Health.

\section{Publisher's Note}

Springer Nature remains neutral with regard to jurisdictional claims in published maps and institutional affiliations.

\section{Author details}

${ }^{1}$ Department of Clinical Sciences, Diabetes and Celiac disease unit, Lund University, Clinical Research Centre, Jan Waldenströms gata 35, 20502 Malmö, Sweden. ${ }^{2}$ Center for Biotechnology and Genomic Medicine, Medical College of Georgia, Augusta University, Augusta, GA, USA. ${ }^{3}$ Health Informatics Institute, Morsani College of Medicine, University of South Florida, Tampa, FL, USA. ${ }^{4}$ Barbara Davis Center for Childhood Diabetes, University of Colorado, Aurora, CO, USA. ${ }^{5}$ Pacific Northwest Diabetes Research Institute, Seattle, WA, USA. 'Department of Physiology, Institute of Biomedicine, University of Turku, and Department of Pediatrics, Turku University Hospital, Turku, Finland. ${ }^{7}$ Institute of Diabetes Research, Helmholtz Zentrum München, and Klinikum rechts der Isar, Technische Universität München, and Forschergruppe Diabetes e.V, Neuherberg, Germany. ${ }^{8}$ National Institute of Diabetes \& Digestive \& Kidney Diseases, Bethesda, MD, USA. ${ }^{9}$ Department of Pediatrics, University of Florida, Gainesville, FL, USA.

Received: 2 February 2017 Accepted: 9 May 2017

Published online: 16 May 2017

\section{References}

1. Taddio A, Manley J, Potash L, Ipp M, Sgro M, Shah V. Routine immunization practices: use of topical anesthetics and oral analgesics. Pediatrics. 2007;120: e637-43. 
2. Mayoral CE, Marino RV, Rosenfeld W, Greensher J. Alternating antipyretics: is this an alternative? Pediatrics. 2000;105:1009-12.

3. Schmitt BD. Fever phobia: misconceptions of parents about fevers. Am J Dis Child. 1980;134:176-81.

4. Casey R, McMahon F, McCormick MC, Pasquariello PS, Zavod W, King FH. Fever therapy: an educational intervention for parents. Pediatrics. 1984;73:600-5.

5. Bilenko N, Tessler H, Okbe R, Press J, Gorodischer R. Determinants of antipyretic misuse in children up to 5 years of age: a cross-sectional study. Clin Ther. 2006;28:783-93.

6. Section on Clinical Pharmacology and Therapeutics, Committee on Drugs, Sullivan JE, Farrar HC. Fever and antipyretic use in children. Pediatrics. 2011;127:580-7.

7. Pedulla MN. Prophylactic use of antipyretic agents with childhood immunizations and antibody response: reason for concern? J Pediatr Health Care. 2012;26:200-3.

8. Chiappini E, Principi N, Longhi R, Tovo P-A, Becherucci P, Bonsignori F, et al. Management of fever in children: summary of the Italian pediatric society guidelines. Clin Ther. 2009;31:1826-43.

9. Bertille N, Fournier-Charrière E, Pons G, Chalumeau M. Managing fever in children: a national survey of parents' knowledge and practices in France. PLoS One. 2013;8:e83469.

10. Hinson JA, Han-Hsu H, Mays JB, Holt SJ, McLean P, Ketterer B. Acetaminophen-induced alterations in blood glucose and blood insulin levels in mice. Res Commun Chem Pathol Pharmacol. 1984:43:381-91.

11. Shertzer Howard G, Schneider Scott N, Kendig Eric L, Clegg Deborah J, D' Alessio David A, Genter Mary Beth. Acetaminophen normalizes glucose homeostasis in mouse models for diabetes. 2008;75:1402-10. Available from: http://www.sciencedirect.com/science/article/pii/S0006295207007988

12. Blough ER, Wu M. Acetaminophen: beyond pain and fever-relieving. Front Pharmacol. Frontiers. 2011;2:72.

13. Wu M, Desai DH, Kakarla SK, Katta A, Paturi S, Gutta AK, et al. Acetaminophen prevents aging-associated hyperglycemia in aged rats: effect of aging-associated hyperactivation of p38-MAPK and ERK1/2. Diabetes Metab Res Rev. 2009;25:279-86. John Wiley \& Sons, Ltd.

14. Cheelo M, Lodge CJ, Dharmage SC, Simpson JA, Matheson M, Heinrich J, et al. Paracetamol exposure in pregnancy and early childhood and development of childhood asthma: a systematic review and meta-analysis. Arch Dis Child. 2015;100:81-9.

15. Kreiner-Møller E, Sevelsted A, Vissing NH, Schoos A-MM, Bisgaard H. Infant acetaminophen use associates with early asthmatic symptoms independently of respiratory tract infections: the Copenhagen prospective study on asthma in childhood 2000 (COPSAC(2000)) cohort. J Allergy Clin Immunol. 2012;130:1434-6.

16. Mork NL, Robertson RP. Effects of nonsteroidal antiinflammatory drugs in conventional dosage on glucose homeostasis in patients with diabetes. West J Med. 1983;139:46-9.

17. Jafarnejad A, Bathaie SZ, Nakhjavani M, Hassan MZ. Investigation of the mechanisms involved in the high-dose and long-term acetyl salicylic acid therapy of type I diabetic rats. J Pharmacol Exp Ther. 2008;324:850-7.

18. Bushra R, Aslam N. An overview of clinical pharmacology of ibuprofen. Oman Med J. 2010;25:155-661.

19. TEDDY Study Group. The environmental determinants of diabetes in the young (TEDDY) study. Ann N Y Acad Sci. 2008;1150:1-13.

20. TEDDY Study Group. The environmental determinants of diabetes in the young (TEDDY) study: study design. Pediatr Diabetes. 2007;8:286-98. Blackwell Publishing Ltd.

21. Lönnrot M, Lynch K, Larsson HE, Lernmark $\AA$, Rewers M, Hagopian W, et al. A method for reporting and classifying acute infectious diseases in a prospective study of young children: TEDDY. BMC Pediatr. 2015;15:24.

22. Bonifacio E, Yu L, Williams AK, Eisenbarth GS, Bingley PJ, Marcovina SM, et al. Harmonization of glutamic acid decarboxylase and islet antigen-2 autoantibody assays for national institute of diabetes and digestive and kidney diseases consortia. J Clin Endocrinol Metab. 2010;95:3360-7.

23. Babaya N, Yu L, Miao D, Wang J, Rewers M, Nakayama M, et al. Comparison of insulin autoantibody: polyethylene glycol and micro-IAA 1-day and 7-day assays. Diabetes Metab Res Rev. 2009;25:665-70.

24. Törn C, Mueller PW, Schlosser M, Bonifacio E, Bonifacio EE, Bingley PJ, et al. Diabetes antibody standardization program: evaluation of assays for autoantibodies to glutamic acid decarboxylase and islet antigen-2. Diabetologia. 2008:51:846-52.

25. Roivainen M, Klingel K. Virus infections and type 1 diabetes risk. Curr Diab Rep. 2010;10:350-6.
26. Ziegler AG, Hillebrand B, Rabl W, Mayrhofer M, Hummel M, Mollenhauer U, et al. On the appearance of islet associated autoimmunity in offspring of diabetic mothers: a prospective study from birth. Diabetologia. 1993;36:402-8.

27. She J-X. Susceptibility to type I diabetes: HLA-DQ and DR revisited. Immunol Today. 1996;17:323-9.

28. Kimpimäki T, Erkkola M, Korhonen S, Kupila A, Virtanen SM, llonen J, et al. Short-term exclusive breastfeeding predisposes young children with increased genetic risk of type I diabetes to progressive beta-cell autoimmunity. Diabetologia. 2001;44:63-9.

29. Virtanen SM, Kenward MG, Erkkola M, Kautiainen S, Kronberg-Kippilä C, Hakulinen $\mathrm{T}$, et al. Age at introduction of new foods and advanced beta cell autoimmunity in young children with HLA-conferred susceptibility to type 1 diabetes. Diabetologia. 2006;49:1512-21.

30. Uusitalo U, Liu X, Yang J, Aronsson CA, Hummel S, Butterworth M, et al. Association of Early Exposure of Probiotics and islet autoimmunity in the TEDDY study. JAMA Pediatr. 2015;170:1-9.

31. Törn C, Hadley D, Lee HS, Hagopian W, Lernmark $\AA$, Simell O, et al. Role of type 1 diabetes associated SNPs on risk of autoantibody positivity in the TEDDY study. Diabetes. 2014;64(5):1818-29.

32. Litherland SA, She J-X, Schatz D, Fuller K, Hutson AD, Peng RH, et al. Aberrant monocyte prostaglandin synthase 2 (PGS2) expression in type 1 diabetes before and after disease onset. Pediatr Diabetes. 2003:4:10-8. Munksgaard International Publishers

33. Beyan H, Buckley LR, Bustin SA, Yousaf N, Pozzilli P, Leslie RD. Altered monocyte cyclo-oxygenase response in non-obese diabetic mice. Clin Exp Immunol. 2009;155:304-10.

34. Eyers $S$, Weatherall $M$, Jefferies $S$, Beasley R. Paracetamol in pregnancy and the risk of wheezing in offspring: a systematic review and meta-analysis. Clin Exp Allergy. 2011;41:482-9.

35. Prymula R, Siegrist C-A, Chlibek R, Zemlickova H, Vackova M, Smetana J, et al. Effect of prophylactic paracetamol administration at time of vaccination on febrile reactions and antibody responses in children: two open-label, randomised controlled trials. Lancet. 2009:374:1339-50. Elsevier Ltd

36. Sullivan JE, Farrar HC. The section on clinical pharmacology and therapeutics, committee on drugs. Fever and antipyretic use in children. Pediatrics. 2011;127:580-7.

37. Erlewyn-Lajeunesse MDS, Coppens K, Hunt LP, Chinnick PJ, Davies P, Higginson IM, et al. Randomised controlled trial of combined paracetamol and ibuprofen for fever. Arch Dis Child. 2006;91:414-6.

38. Joos S, Musselmann B, Szecsenyi J. Integration of complementary and alternative medicine into family practices in Germany: results of a national survey. Evid Based Complement Alternat Med. 2011;2011:495813.

39. Barnes PM, Bloom B, Nahin RL. Complementary and alternative medicine use among adults and children: United States, 2007. Natl Health Stat Report. 2008;10(12):1-23.

\section{Submit your next manuscript to BioMed Central and we will help you at every step:}

- We accept pre-submission inquiries

- Our selector tool helps you to find the most relevant journal

- We provide round the clock customer support

- Convenient online submission

- Thorough peer review

- Inclusion in PubMed and all major indexing services

- Maximum visibility for your research

Submit your manuscript at www.biomedcentral.com/submit 